\title{
Geração de resíduos de madeira e derivados da indústria moveleira em função das variáveis de produção
}

\author{
Éverton Hillig Universidade de Caxias do Sul \\ Vania Elisabete Schneider Universidade de Caxias do Sul \\ Eloide Teresa Pavoni Universidade de Caxias do Sul
}

\section{RESUMO}

Os processos produtivos da cadeia madeira-móveis geram quantidades significativas de resíduos de madeira, os quais nem sempre têm uma destinação correta. 0 potencial de aproveitamento destes resíduos é significativo, quer seja como matéria-prima secundária, quer seja pelo seu potencial energético. $\mathrm{O}$ gerenciamento dos resíduos é um dos desafios à gestão e ao desempenho ambiental das empresas. Neste trabalho, utilizou-se a análise multivariada, com extração de componentes principais, para analisar os carregamentos de cada variável original e identificar as principais variáveis que apresentam similaridades em relação à geração de resíduos. As variáveis de produção consideradas foram: quantidade de matéria-prima consumida, número de colaboradores, número de máquinas, consumo de energia e consumo de água. Por meio de regressão linear, utilizando o método stepwise, foram obtidas as equações de estimativa dos resíduos em função das variáveis de produção originais, resultando na quantidade de resíduo gerado por classe de matéria-prima, para determinada empresa ou determinado município pesquisado. A estimativa de geração foi aplicada ao Pólo Moveleiro da Serra Gaúcha/RS.

\section{Generation of wood waste and derivatives on furniture industry related to production's variables}

\begin{abstract}
The production processes of furniture industry generate significant amounts of wood waste, which has not always a correct destination. The potential for exploitation of these residues is significant, whether as secondary raw material, whether by its energy potential. The management of this waste is one of the challenges for the management and environmental performance of companies. This work used multivariate analysis with the extraction of key components, to analyze the load of each original variable and identify key variables that have similarities in relation to the waste generation. The variables of production considered was: quantity of raw materials consumed, number of employees, number of machines, energy consumption and water consumption. By linear regression, using the stepwise method, were obtained the equations to estimate the waste according to the original variables of production. With these results is possible to calculate the amount of waste generated by class of raw material for a particular company or municipality researched. The estimate of generation was applied to the furniture industries located on Serra Gaúcha / RS.
\end{abstract}

\section{KEY WORDS}

Waste management, wood waste, furniture industry, environmental management. 


\section{INTRODUÇÃO}

A cadeia produtiva madeira-móveis gera uma significativa quantidade de resíduos de madeira que, embora muitas vezes seja aproveitada para alguns fins específicos, pode se constituir num problema de gestão ambiental das empresas. Embora a maior perda de madeira na forma de resíduo ocorra em seu processamento primário, nas indústrias de móveis podem ocorrer perdas nas operações de corte e de acabamento.

Segundo Moraes (2002), a indústria de móveis pode ser segmentada em função da matéria-prima que utiliza ou do uso final dos móveis que produz. Como existem diferentes tipos de matérias-primas à base de madeira utilizadas na fabricação de diferentes tipos de móveis, as empresas moveleiras apresentam diferentes características e produzem diferentes resíduos de madeira e de seus derivados. Em geral, esses resíduos se apresentam na forma de serragem e de retalhos e seu aproveitamento tem sido principalmente para geração de energia.

No Estado do Rio Grande do Sul, a indústria moveleira tem uma expressiva participação na economia, principalmente na região da Serra Gaúcha. Conforme Roese (2000), embora no conjunto da indústria de transformação a participação do setor seja modesta, o fato de constituir pólos regionais faz com que assuma grande importância em determinadas regiões. A indústria moveleira gaúcha está concentrada na região da Serra Gaúcha, com um pólo em Bento Gonçalves, que responde por $45 \%$ da produção estadual. A madeira oriunda de reflorestamentos e os painéis de madeira são os principais produtos utilizados na fabricação e, apesar da alta tecnologia empregada, as perdas ainda são altas, principalmente decorrentes dos cortes primários dos painéis e das operações de beneficiamento da madeira serrada.

Para propor alternativas de aproveitamento aos resíduos de madeira e seus derivados gerados no polo moveleiro, que agreguem maior valor aos resíduos, torna-se fundamental conhecer em primeiro lugar os tipos e quantidades de resíduos gerados. Sendo assim, este trabalho tem por objetivo analisar a possibilidade de estimar os resíduos de madeira e derivados gerados na indústria moveleira em função de algumas variáveis de produção facilmente observáveis.

\section{REFERENCIAL TEÓRICO}

\subsection{A cadeia produtiva de madeira e móveis}

Segundo Guéron e Garrido (2004) a indústria de madeira e móveis deve ser entendida como parte do setor de base florestal, que compreende ainda o segmento de papel e celulose e de lenha e carvão vegetal. A partir de um primeiro processo de transformação industrial, a indústria da madeira pode ser desdobrada em indústrias de serrados, painéis de madeira reconstituída, remanufaturados e a indústria de móveis. Esta última compreende um segundo processo de beneficiamento, originando produtos com maior valor agregado.

De acordo com IBQP (2002), a cadeia produtiva da madeira pode ser segmentada em três grandes vertentes, se considerados os distintos usos finais: a cadeia do processamento mecânico, a do papel e celulose e a da energia, representada pela lenha e carvão vegetal. A cadeia de processamento mecânico caracteriza-se pela utilização da madeira bruta e a aplicação de processos mecânicos para seu desdobramento em três tipos básicos, que podem ser definidos como laminação, produção de painéis e desdobro de toras.

Considerando a Cadeia de Processamento Mecânico, Gonçalves (2000) classifica os processos de usinagem da madeira em abate, descascamento, desdobro, laminação, produção de partículas e beneficiamento. Cada um desses processos é formado por diversas operações, as quais definem o trabalho de transformação da forma da madeira num determinado processo, como por exemplo, as operações de corte, seja com uma serra de fita na serraria ou com uma seccionadora na indústria de móveis seriados.

Moraes (2002) cita que a indústria moveleira pode ser segmentada tanto em função dos materiais de que os móveis são confeccionados, como também de acordo com os usos a que se destinam. Quanto aos usos, existem os móveis de madeira para residência (que contemplam os móveis retilíneos seriados, os móveis torneados seriados e móveis sob medida) e os móveis para escritório (móveis sob encomenda e móveis seriados).

O subsistema da indústria moveleira depende, a montante, da indústria siderúrgica, fornecedora de metais para móveis, da indústria química, fornecedora de colas, tintas, PVC, vernizes e vidro, da indústria de couro, indústria têxtil e da indústria responsável pelo processamento da madeira. Desses grupos, entretanto, o do processamento mecânico da madeira fornece a parcela mais significativa de insumos que acabarão por gerar resíduos.

\subsection{Resíduos de madeira da cadeia produtiva madeira-móveis}

Brand e Hassegawa (2005), num trabalho para determinação da quantidade de resíduos madeiráveis gerados nas indústrias madeireiras em um raio de $150 \mathrm{~km}$ do município de Otacílio Costa, verificaram que os resíduos gerados em maior quantidade pelas empresas da região são: cavaco com casca, resíduos de lâminas, serragem e rolo-resto. As atividades com maior representação na produção de resíduos são 
as serrarias e laminadoras, que se constituem em indústrias de transformação primária da madeira, e que produzem em torno de $80 \%$ do volume total de resíduos.

$\mathrm{A}$ indústria de lâminas de madeira e do compensado também tem como base toras provenientes de florestas naturais ou de florestas plantadas. Da mesma forma que no caso da madeira serrada, é necessária uma boa qualidade em relação às propriedades físico-mecânicas da madeira e às dimensões das toras. Nesse segmento, os resíduos resultantes podem alcançar mais de $50 \%$ do volume das toras que lhes deram origem (RADIOBRÁS, 1997).
Outros autores igualmente investigaram o segmento de compensados, visando determinar e quantificar as perdas no processo. Koch (1976), determinou que de uma tonelada de toras de coníferas já descascadas se obtém 0,45 tonelada de compensado sem lixamento e com cola, 0,06 tonelada de lâminas aplainadas para uso em miolos de painéis, 0,08 tonelada de partículas para uso em chapas de partículas, 0,30 tonelada de partículas para uso em polpa e 0,12 tonelada de partículas para uso como combustível.

Ecker et al. (2003), por sua vez, trabalhando com painéis compensados sarrafeados, encontraram um rendimento de $43,75 \%$ para todo o processo produtivo, desde o corte dos sarrafos verdes.

Os estudos de Brand et al. (2004) acerca das diversas operações de uma indústria de painéis de compensado sarrafeado determinaram os rendimentos médios de cada operação. Nesse segmento, por meio da metodologia do balanço de material, os autores

Segundo Food and Agriculture Organization - FAO (1968), citado por Silva (1987), para a fabricação de $1 \mathrm{~m}^{3}$ de lâminas é necessário $1,9 \mathrm{~m}^{3}$ de toras de madeira, perfazendo um aproveitamento de 52,6\%. Para cada $1 \mathrm{~m}^{3}$ de compensado, considerando toda cadeia produtiva desse segmento industrial, necessita-se de $2,3 \mathrm{~m}^{3}$ de toras de madeira, o que resulta num aproveitamento de $43,5 \%$.

Olandoski (2001) ressalta que as fontes de resíduos no processo de fabricação do compensado podem estar atreladas à qualidade das lâminas, ao processo produtivo como um todo, às características do equipamento e ao comprometimento do operador com a operação. Dessa forma, são essas as principais variáveis que devem ser levadas em consideração quando da caracterização dos resíduos.

Segundo Polzl (2002), a geração de resíduo na fabricação do compensado varia de $15,13 \%$ a $12,55 \%$, dependendo do tamanho da empresa e considerando os desperdícios depois da secagem das lâminas. A perda de insumos durante o processo produtivo de fabricação de compensados, estratificada por tamanho da empresa, proposta pelo autor é apresentada na Tabela 1.

Tabela 1: Perdas no processo de produção da indústria do compensado, estratificado por tamanho da empresa.

\begin{tabular}{cc}
\hline PRODUÇÃO & PERDAS NO PROCESSO (\%) \\
\hline Pequenas & 15,13 \\
\hline Médias & 14,55 \\
Grandes & 12,55 \\
\hline
\end{tabular}

Fonte: Polzl (2002) demonstraram que a atividade de manufatura de painéis que mais contribui para a geração de resíduos é a preparação dos sarrafos de madeira sólida para a coladeira, que inclui a classificação de madeiras. Por outro lado, a etapa de usinagem com menor geração de resíduos foi a seccionadora, o que, segundo os autores, se deve em grande parte ao pequeno volume de painéis que passa por essa etapa. Foi verificado também que apenas $18,66 \%$, em média, dos resíduos gerados são vendidos, sendo o restante queimado na caldeira.

Segundo o Instituto Pró-Natura (2002), existem por volta de 2.500 empresas na região amazônica, que produzem aproximadamente 9,7 milhões de $\mathrm{m}^{3}$ de produtos madeireiros anualmente, dos quais, $63 \%$ destinados à construção civil. Arima et al. (1999) citam que essas empresas geram um grande volume de resíduos de madeira, considerando desde a tora no pátio da empresa até as pranchas serradas, compensados ou laminados, estimado entre 60 e $68 \%$ do volume de madeira bruta processada. De acordo com os autores, a baixa produtividade deve-se ao equipamento obsoleto, às formas inadequadas de armazenar toras e à falta generalizada de atividades que visem o aproveitamento de aparas de madeira.

Gerwing et al. (2001) examinaram os fatores que influenciam o rendimento do processamento de toras em dez serrarias e duas laminadoras em Paragominas, na Amazônia Oriental. Segundo os autores, os rendimentos médios totais foram maiores para as laminadoras (39\%), seguindo-se as serrarias que produzem para o mercado doméstico (36\%) e as de exportação (32\%). Os autores observaram que uma variedade de fatores influencia o rendimento do processamento de toras, como a degradação durante o armazenamento, 
danos causados por insetos e a variação na espessura da madeira processada, resultante da utilização de equipamentos de processamento inadequados ou gastos. Por essa razão, encontraram grandes diferenças entre os rendimentos de cada serraria, sendo o maior valor igual a $55 \%$ e o menor igual a $27 \%$. O rendimento das empresas madeireiras foi maior (em até $10 \%$ do volume total da tora) para aquelas que usavam sobras de madeira ou de laminados para fabricar produtos secundários.

\subsubsection{Resíduos de madeira da indústria moveleira}

Poucos são os trabalhos que analisaram a geração de resíduos nas indústrias moveleiras. Hillig et al. (2004) realizaram o diagnóstico da geração de resíduos do polo moveleiro da Serra Gaúcha, objetivando estimar a quantidade de resíduo de madeira e derivados gerados, que serviu de base para a primeira fase deste trabalho. A Tabela 2 apresenta as quantidades de matérias-primas de madeiras consumidas pelas empresas amostradas e as médias de aproveitamento para cada classe de matériaprima, calculadas em médias proporcionais ao consumo de cada empresa.

Os autores comentam que, com relação às principais matérias-primas, madeiras e derivados, utilizadas, verifica-se ainda uma predominância do uso de chapas aglomeradas, seguidas, em ordem de consumo, pelo uso de MDF, madeira serrada e compensado. A utilização de determinada matéria-prima está relacionada às linhas de produtos fabricadas, sendo que o aglomerado atende principalmente à produção de móveis retilíneos seriados.

Nota-se que as médias de aproveitamento de cada matéria-prima utilizada estão numa faixa estreita de variação, com exceção do município de Lagoa Vermelha para a matéria-prima madeira, onde o aproveitamento apresenta uma média maior. Esse fato deve-se a três empresas desse município que se dedicam apenas à montagem dos móveis, não gerando resíduos de processamento da madeira.

Na Tabela 3 são apresentadas as quantidades de resíduos gerados de serragem, maravalhas e retalhos, onde se verifica que Flores da Cunha apresenta uma elevada geração de resíduos de serragem em comparação com a proporção de matéria-prima consumida. Este fato decorre de que duas empresas amostradas neste município trabalham com madeira serrada de pinus para produção de móveis seriados. Assim, além da maior perda que ocorre no beneficiamento da madeira serrada, o volume a granel de serragem produzida é aumentado pela baixa massa específica da madeira.

\section{E quações de regressão linear que fornecessem estimativas da quantidade de resíduos gerados nas empresas em função das variáveis de produção originais.}

A Tabela 4 apresenta os valores estimados da geração de resíduos por classe de matéria-prima e por município para as empresas amostradas. Os dados estimados podem ser facilmente estendidos para a produção total do município ou mesmo do Estado, se for considerada a proporção da amostra em relação à produção do município e a participação de cada município na produção estadual.

Além das estimativas da geração de resíduos, o trabalho identificou as principais espécies de madeiras utilizadas como madeira serrada e apresenta também um valor médio

Tabela 2: Matérias-primas, madeira e derivados, consumidos pelas empresas amostradas e médias proporcionais de aproveitamento.

\begin{tabular}{|c|c|c|c|c|c|c|c|c|c|c|}
\hline MUNICÍPIO & $\mathrm{N}$ & $\begin{array}{l}\text { MAD. } \\
\left(\mathrm{m}^{3}\right)\end{array}$ & $\begin{array}{l}\text { APR. } \\
(\%)\end{array}$ & $\begin{array}{l}\text { MDF } \\
\left(\mathrm{m}^{3}\right)\end{array}$ & $\begin{array}{l}\text { APR. } \\
(\%)\end{array}$ & $\begin{array}{l}\text { AGL. } \\
\left(\mathrm{m}^{3}\right)\end{array}$ & $\begin{array}{l}\text { APR. } \\
(\%)\end{array}$ & $\begin{array}{c}\text { COMP. } \\
\left(\mathrm{m}^{3}\right)\end{array}$ & $\begin{array}{l}\text { APR. } \\
(\%)\end{array}$ & $\begin{array}{l}\text { TOT. } \\
\left(\mathrm{m}^{3}\right)\end{array}$ \\
\hline Bento Gonçalves & 27 & 2057,0 & 68,18 & 5029,5 & 94,99 & 19504,5 & 93,59 & 319,4 & 94,98 & 26910,4 \\
\hline Caxias do Sul & 35 & 2144,3 & 63,89 & 217,5 & 91,49 & 236,0 & 94,69 & 2497,5 & 93,82 & 5025,3 \\
\hline Flores da Cunha & 14 & 2766,5 & 63,05 & 2110,3 & 92,55 & 1621,7 & 91,36 & 46,8 & 89,55 & 6542,8 \\
\hline Lagoa Vermelha & 18 & 538,0 & 88,38 & 4541,8 & 94,51 & 4276,5 & 94,9 & 30,5 & 92,38 & 9386,8 \\
\hline TOTAIS & 94 & 7505,8 & 66,51 & 11899,1 & 94,31 & 25638,7 & 93,68 & 2894,2 & 93,86 & 47865,3 \\
\hline
\end{tabular}

Legenda: N - Número de empresas visitadas; MAD - Madeira; APR - Aproveitamento; MDF - Medium Density Fiberboard/Fibra de média densidade; AGL Aglomerado; COMP - Compensado; TOT - Total de matéria-prima consumida.

Fonte: Hillig et al. (2004) 
da densidade a granel das diferentes classes de resíduos. Como madeiras serradas são usadas madeiras de Pinus taeda, Eucalyptus sp., Apuleia leiocarpa (garapeira) e Tabebuia cassinoides (caixeta). Os valores médios de densidade a granel citados para as diferentes classes de resíduos são:

- Serragem $($ em geral $)=223 \mathrm{~kg} / \mathrm{m}^{3}$

- Serragem de $\mathrm{MDF}=190 \mathrm{~kg} / \mathrm{m}^{3}$

- Serragem de aglomerado $=265 \mathrm{~kg} / \mathrm{m}^{3}$

- Serragem de madeira serrada $=216 \mathrm{~kg} / \mathrm{m}^{3}$

Com relação ao destino ou aproveitamento, Schneider et al. (2004) verificaram que uma parcela expressiva dos resíduos, igual a 6,7\%, ainda é descartada para queima, sem aproveitamento. Outra parcela, que corresponde a 8,3\% dos resíduos gerados, é doada, não agregando valor nenhum nesta operação. A Figura 1 apresenta o destino do resíduo de madeira e derivados das indústrias do polo moveleiro da Serra Gaúcha.

LIMA (2005) num trabalho com o objetivo de verificar o desempenho ambiental das indústrias de móveis de ma- deira situadas no polo moveleiro de Arapongas, verificou que, de todos os resíduos gerados, os resíduos em maior quantidade são os resíduos de madeira, respondendo por $85 \%$ dos resíduos totais gerados. Desses resíduos, como pedaços, pó e cepilho, boa parte são destinados para confecção de briquetes. O autor comenta que no geral $82 \%$ das empresas pesquisadas aproveitam algum tipo de resíduo no próprio processo, $53 \%$ vendem parte dos resíduos e apenas $6 \%$ os queimam.

\section{METODOLOGIA}

\subsection{Diagnóstico da geração de resíduos do polo moveleiro}

O diagnóstico da geração de resíduos do polo moveleiro da Serra Gaúcha forneceu os dados para determinação dos tipos e quantidade de resíduos disponíveis. Esses dados, também serviram para testar modelos matemáticos, visando

Tabela 3: Quantidades de resíduos de madeira e derivados gerados nas empresas visitadas.

\begin{tabular}{ccccc}
\hline MUNICÍPIO & $\mathrm{N}^{1}$ & $\begin{array}{c}\text { SERRAGEM } \\
\left(\mathrm{m}^{3}\right)\end{array}$ & $\begin{array}{c}\text { MARAVALHAS } \\
\left(\mathrm{m}^{3}\right)\end{array}$ & $\begin{array}{c}\text { RETALHOS }^{2} \\
\left(\mathrm{~m}^{3}\right)\end{array}$ \\
\hline Bento Gonçalves & 27 & 2558,2 & 131,5 & 2444,6 \\
Caxias do Sul & 35 & 485,9 & 159,2 & 191,2 \\
Flores da Cunha & 14 & 2619,5 & 3935,6 & 599,5 \\
Lagoa Vermelha & 18 & 495,0 & 851,0 & 213,5 \\
Totais & $\mathbf{9 4}$ & $\mathbf{6 1 5 8 , 6}$ & $\mathbf{5 0 7 7 , 3}$ & $\mathbf{3 4 4 8 , 8}$ \\
\hline
\end{tabular}

${ }^{1}$ Número de empresas visitadas.

${ }^{2}$ Quantidades de resíduos gerados, dados em volume a granel.

Fonte: Hillig et al. (2004).

Tabela 4: Estimativa dos volumes mensais dos resíduos gerados por classe de matéria-prima e por município nas empresas visitadas.

\begin{tabular}{|c|c|c|c|c|c|c|c|c|c|c|}
\hline \multirow[t]{2}{*}{ MUNICÍPIO } & \multicolumn{3}{|c|}{ MADEIRA } & \multicolumn{3}{|c|}{ MDF } & \multicolumn{2}{|c|}{ AGLOMERADO } & \multicolumn{2}{|c|}{ COMPENSADO } \\
\hline & $\mathrm{S}\left(\mathrm{m}^{3}\right)$ & $\mathrm{M}\left(\mathrm{m}^{3}\right)$ & $\mathrm{R}\left(\mathrm{m}^{3}\right)$ & $\mathrm{S}\left(\mathrm{m}^{3}\right)$ & $\mathrm{M}\left(\mathrm{m}^{3}\right)$ & $\mathrm{R}\left(\mathrm{m}^{3}\right)$ & $\mathrm{S}\left(\mathrm{m}^{3}\right)$ & $\mathrm{R}\left(\mathrm{m}^{3}\right)$ & $\mathrm{S}\left(\mathrm{m}^{3}\right)$ & $\mathrm{R}\left(\mathrm{m}^{3}\right)$ \\
\hline Bento Gonçalves & 771 & 93 & 736 & 297 & 38 & 283 & 1472 & 1407 & 19 & 18 \\
\hline Caxias do Sul & 392 & 156 & 154 & 9 & 3 & 4 & 6 & 2 & 78 & 31 \\
\hline Flores da Cunha & 2022 & 3385 & 463 & 311 & 551 & 71 & 277 & 63 & 10 & 2 \\
\hline Lagoa Vermelha & 58 & 170 & 25 & 232 & 681 & 100 & 203 & 87 & 2 & 1 \\
\hline Totais & 3243 & 3804 & 1378 & 849 & 1273 & 458 & 1958 & 1559 & 109 & 52 \\
\hline
\end{tabular}

Legenda: $\mathrm{S}=$ Volume a granel de serragem gerada; $\mathrm{M}=$ Volume a granel de maravalha gerada; $\mathrm{R}=$ Volume a granel de retalhos gerados .

Fonte: HILLIG et al. (2004) 
estimar a geração de resíduos de madeira em função de variáveis de produção. Essa análise serviu de base para escolha dos tipos de serragem usados nos experimentos, bem como forneceu uma estimativa da disponibilidade de serragem por município.

\subsubsection{Quantidade de resíduo de madeira e derivados disponíveis}

Para estimativa das quantidades totais de resíduos gerados por classe de matéria-prima e tipo de resíduo, para cada município pesquisado, foram considerados as quantidades de matérias-primas utilizadas, seu aproveitamento e as quantidades de resíduos gerados. Utilizando os dados da Tabela 4 (vide seção 2.2.1), os volumes de serragem foram convertidos para massa por meio da densidade média a granel de cada tipo, e estendidos para a produção total do município, considerando a produção de cada município amostrada.

\subsubsection{Estimativa da quantidade de resíduo de ma- deira e derivados gerados, em função das variáveis de produção}

$\mathrm{Na}$ análise da geração de resíduos por empresa foi utilizada a técnica estatística multivariada de extração dos componentes principais, que possibilitou identificar as principais variáveis que apresentam similaridades em relação à geração de resíduos. Foram selecionadas 16 variáveis entre as pesquisadas, quais sejam:

- Consumo de madeira $\left(\mathrm{m}^{3}\right)$

- Resíduo de madeira $\left(\mathrm{m}^{3}\right)$

- Consumo de $\operatorname{MDF}\left(\mathrm{m}^{3}\right)$

- Resíduo de $\operatorname{MDF}\left(\mathrm{m}^{3}\right)$

- Consumo de Aglomerado $\left(\mathrm{m}^{3}\right)$

- Resíduo de aglomerado $\left(\mathrm{m}^{3}\right)$

- Consumo de compensado $\left(\mathrm{m}^{3}\right)$

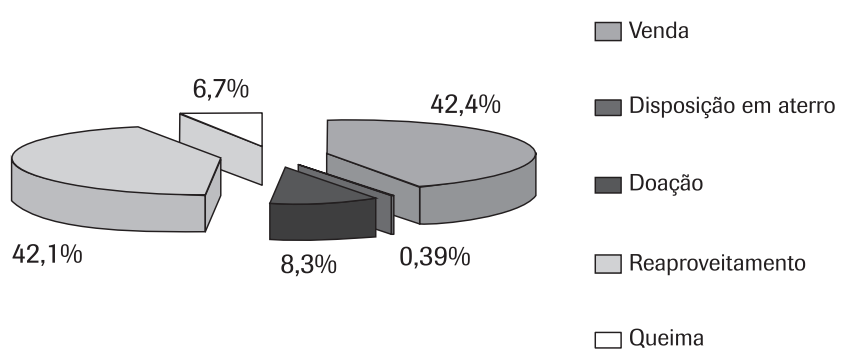

Figura 1: Destino do resíduo de madeira e derivados das indústrias do polo moveleiro da Serra Gaúcha.

Fonte: Schneider et al. (2004)
- Resíduo de compensado $\left(\mathrm{m}^{3}\right)$

- Consumo de matéria-prima $\left(\mathrm{m}^{3}\right)$

- Número de colaboradores

- Número de máquinas

- Consumo de energia $(\mathrm{Kw})$

- Consumo de água $\left(\mathrm{m}^{3}\right)$

- Total de serragem $\left(\mathrm{m}^{3}\right)$

- Total de maravalhas $\left(\mathrm{m}^{3}\right)$

- Total de retalhos $\left(\mathrm{m}^{3}\right)$

Com base na análise multivariada, essas variáveis foram utilizadas para obter modelos de estimativa da quantidade de resíduo gerada, em função das variáveis de produção. Pelo método stepwise, foram selecionadas as variáveis que melhor se ajustam para estimar por regressão linear os resíduos de madeira, MDF, aglomerado e compensado. Todas as análises estatísticas foram realizadas com software SPSS.

\section{RESULTADOS E DISCUSSÃO}

\subsection{Estimativa da quantidade de serragem gerada por município}

A Tabela 5 apresenta a estimativa da quantidade mensal de serragem gerada, por município e por classe de matériaprima, expressa em massa (toneladas) ao teor de umidade de equilíbrio. Verifica-se que existe uma quantidade significativa de serragem de madeira serrada, de aglomerado e de MDF em todos os municípios pesquisados, com exceção de Caxias do Sul. Por exemplo, a quantidade de resíduo de MDF gerada em Bento Gonçalves, se usada em compósitos com HDPE na proporção de 30\%, pode fornecer matériaprima para produção de 470,25 toneladas de compósitos reforçados por mês.

\subsection{Modelos para estimativa da geração de resíduos em função das variáveis de produção}

Das variáveis diagnosticadas, foram selecionadas $16 \mathrm{e}$ aplicado o método fatorial de análise multivariada para extração dos componentes principais. A Tabela 6 apresenta a variância explicada pelo cálculo dos autovalores de cada um dos componentes resultantes, realizado pelo software SPSS. Verifica-se que existe similaridade entre as variáveis selecionadas, pois apenas cinco componentes principais explicam $91,05 \%$ da variância total entre as variáveis selecionadas.

$\mathrm{Na}$ Tabela 7 são apresentadas as variáveis selecionadas e seus carregamentos em cada um dos cinco componentes principais extraídos. É possível verificar que o componente 1 apresenta a maioria das variáveis com valores de carrega- 
mento acima de 0,500. Esse fato mostra que, embora as indústrias de móveis constituam um universo que abrange diversas matérias-primas e diferentes processos de produção, quase todas as variáveis selecionadas têm um alto valor de carregamento no componente 1 , que pode ser denominado de componente porte da empresa.

Os outros componentes principais da Tabela 7 mostram similaridades entre as variáveis que representam o tipo de matéria-prima consumida e a respectiva geração de resíduos dessa matéria-prima e também separam os componentes pelo tipo de matéria-prima consumida. No componente principal 2, os maiores carregamentos são para consumo de madeira, resíduos de madeira e total de maravalhas. Esse componente pode ser denominado fator matéria-prima madeira e se refere às empresas que trabalham com madeira serrada. Da mesma forma, os componentes principais 3 e 4 referem-se aos fatores compensado e MDF, respectivamente. O componente 5 , por fim, não apresenta valores de carregamentos maiores que 0,500 , mas destacam-se variáveis como o consumo de madeira e resíduos de madeira.

O componente principal 1, que foi denominado porte da empresa, tem como variáveis principais o número de

Tabela 5: Quantidade mensal estimada de serragem gerada pela indústria moveleira em cada um dos municípios pesquisados.

\begin{tabular}{ccccc}
\hline Município & $\begin{array}{c}\text { Madeira } \\
\text { (ton) }\end{array}$ & $\begin{array}{c}\text { MDF } \\
\text { (ton) }\end{array}$ & $\begin{array}{c}\text { Aglomerado } \\
\text { (ton) }\end{array}$ & $\begin{array}{c}\text { Compensado } \\
\text { (ton) }\end{array}$ \\
\hline Bento Gonçalves & 416,34 & 141,08 & 975,20 & 10,59 \\
Caxias do Sul & 211,68 & 4,27 & 3,98 & 43,48 \\
Flores da Cunha & 727,92 & 98,48 & 122,34 & 3,72 \\
Lagoa Vermelha & 25,06 & 88,16 & 107,59 & 0,89 \\
Total & $\mathbf{1 3 8 1 , 0 0}$ & $\mathbf{3 3 1 , 9 9}$ & $\mathbf{1 2 0 9 , 1 1}$ & $\mathbf{5 8 , 6 8}$ \\
\hline
\end{tabular}

Tabela 6: Variância total explicada por cada um dos componentes principais derivados das variáveis selecionadas.

\begin{tabular}{ccccc}
\hline Componente & \multicolumn{3}{c}{ Variância Explicada } \\
\cline { 2 - 3 } \cline { 5 - 5 } \cline { 5 - 5 } \cline { 5 - 5 } \cline { 5 - 5 } 2 & Autovalor & & Variância (\%) & Variância acumulada (\%) \\
\cline { 2 - 3 } 3 & 6,955 & & 43,467 & 43,467 \\
4 & 2,648 & & 16,550 & 60,017 \\
5 & 2,051 & & 12,817 & 72,834 \\
6 & 1,688 & & 10,551 & 83,385 \\
7 & 1,226 & & 7,665 & 91,050 \\
8 & 0,567 & & 3,541 & 94,591 \\
9 & 0,406 & & 2,536 & 97,127 \\
10 & 0,205 & & 1,281 & 98,408 \\
11 & 0,077 & & 0,484 & 98,892 \\
12 & 0,063 & & 0,392 & 99,284 \\
13 & 0,053 & & 0,329 & 99,613 \\
14 & 0,025 & & 0,156 & 99,769 \\
15 & 0,024 & & 0,150 & 99,919 \\
16 & 0.011 & & 0,071 & 99,990 \\
\hline
\end{tabular}


colaboradores, o consumo de matéria-prima e o consumo de energia. Todas as outras variáveis, com exceção do consumo de compensado e do resíduo de compensado, possuem carregamentos significativos nesse componente. A matéria-prima com maior carregamento é o aglomerado e a geração de serragem é mais significativa que a geração de retalhos e de maravalhas.

Isso mostra que a principal matéria-prima utilizada pelas indústrias é o aglomerado, o qual se encontra presente com larga faixa de participação nas indústrias de maior porte. As empresas de maior porte, embora poucas, são responsáveis por grande parte do faturamento do setor e, em consequência, pela geração de grande parcela dos resíduos. A análise concorda com os fatos verificados no trabalho de Alieve e Vargas (2002), que caracterizaram o arranjo moveleiro da serra Gaúcha com uma amostra de 19 empresas pesquisadas. Os autores citam que, embora no cadastro da FIERGS existam 227 empresas localizadas nos municípios pesquisados, as 19 empresas representam $30 \%$ de todo o faturamento da indústria moveleira gaúcha. Em Hierarquia (2000), verificase que apenas uma empresa foi responsável naquele ano por aproximadamente $16 \%$ da representatividade das empresas moveleiras de Bento Gonçalves.
Por essas razões, não foi apropriado fazer uma classificação por um método de agrupamento (por exemplo Cluster), o que seria mais comum numa análise multivariada. Foram testados métodos de agrupamento e obteve-se apenas um grupo com características homogêneas. Dessa forma, se utilizou da extração de componentes principais apenas para analisar os carregamentos de cada variável original e se utilizou de regressão linear com essas varáveis, para se obter equações de estimativa dos resíduos em função das variáveis de produção originais.

A análise da Tabela 7 mostra, ainda, que o consumo de MDF e o resíduo de MDF, embora tenham um carregamento maior no componente 4, possuem um carregamento significativo no componente 1 . Isso vale também para as variáveis consumo de madeira e resíduo de madeira, que no seu caso possuem um carregamento maior no componente 2. Esse fato decorre de que a maioria das empresas não utiliza apenas uma matéria-prima. Principalmente as empresas que têm como matéria-prima principal o aglomerado, utilizam também o MDF e/ou a madeira serrada. Os componentes principais 2 e 4 na verdade representam as empresas que têm como principal matéria-prima esses materiais. Em relação ao uso do compensado essa afir-

Tabela 7: Carregamentos estimados de cada variável selecionada em cada um dos componentes principais extraídos.

\begin{tabular}{|c|c|c|c|c|c|}
\hline \multirow[t]{2}{*}{ Variável } & \multicolumn{5}{|c|}{ Componente } \\
\hline & 1 & 2 & 3 & 4 & 5 \\
\hline Consumo de madeira $\left(\mathrm{m}^{3}\right)$ & 0,555 & 0,629 & 0,037 & $-0,170$ & 0,431 \\
\hline Resíduo de madeira $\left(\mathrm{m}^{3}\right)$ & 0,516 & 0,622 & 0,033 & $-0,202$ & 0,471 \\
\hline Consumo de MDF $\left(\mathrm{m}^{3}\right)$ & 0,428 & $-0,149$ & $-0,158$ & 0,841 & 0,060 \\
\hline Resíduo de MDF $\left(\mathrm{m}^{3}\right)$ & 0,538 & $-0,049$ & $-0,162$ & 0,810 & 0,042 \\
\hline Consumo de Aglomerado $\left(\mathrm{m}^{3}\right)$ & 0,709 & $-0,632$ & $-0,030$ & $-0,269$ & 0,031 \\
\hline Resíduo de aglomerado $\left(\mathrm{m}^{3}\right)$ & 0,751 & $-0,589$ & $-0,045$ & $-0,228$ & 0,011 \\
\hline Consumo de compensado $\left(\mathrm{m}^{3}\right)$ & 0,031 & $-0,025$ & 0,989 & 0,136 & 0,005 \\
\hline Resíduo de compensado $\left(\mathrm{m}^{3}\right)$ & 0,030 & $-0,023$ & 0,989 & 0,135 & 0,007 \\
\hline Consumo de $\mathrm{MP}^{*}\left(\mathrm{~m}^{3}\right)$ & 0,846 & $-0,460$ & 0,117 & 0,042 & 0,130 \\
\hline Número de colaboradores & 0,969 & 0,059 & 0,112 & $-0,055$ & $-0,069$ \\
\hline Número de máquinas & 0,646 & 0,270 & 0,060 & $-0,150$ & $-0,607$ \\
\hline Consumo de energia $(\mathrm{kW})$ & 0,810 & 0,013 & $-0,011$ & $-0,068$ & $-0,105$ \\
\hline Consumo de água $\left(\mathrm{m}^{3}\right)$ & 0,750 & 0,360 & $-0,035$ & $-0,068$ & $-0,513$ \\
\hline Total de serragem $\left(\mathrm{m}^{3}\right)$ & 0,818 & 0,291 & $-0,049$ & 0,052 & $-0,101$ \\
\hline Total de maravalhas $\left(\mathrm{m}^{3}\right)$ & 0,620 & 0,542 & $-0,058$ & 0,120 & 0,176 \\
\hline Total de retalhos $\left(\mathrm{m}^{3}\right)$ & 0,704 & $-0,546$ & $-0,031$ & $-0,199$ & 0,327 \\
\hline
\end{tabular}

${ }^{*}$ Consumo de MP = representa a soma dos consumos de madeira, aglomerado, MDF e compensado de cada uma das empresas. 
mação não é válida e, por isso, as variáveis consumo de compensado e resíduo de compensado têm carregamentos significativos apenas no componente 3 .

Foram testados, ainda, modelos de equações de regressão linear que fornecessem estimativas da quantidade de resíduos gerados nas empresas em função das variáveis de produção originais. A Tabela 8 apresenta os modelos gerados pelo método stepwise, que exclui as variáveis que não possuem uma correlação significativa em cada um dos modelos testados.

\section{Dara os resíduos de madeira e para os resíduos de compensados, a inclusão das variáveis de produção não proporcionou melhora na precisão da estimativa.}

As equações de regressão linear obtidas, além de servirem para estimativa da geração de resíduos nas indústrias moveleiras pesquisadas, complementam as informações obtidas pela análise multivariada. Para os resíduos de madeira e para os resíduos de compensados, a inclusão das variáveis de produção não proporcionou melhora na precisão da estimativa. A estimativa da geração de resíduos de madeira apresentou um coeficiente de determinação $\left(\mathrm{R}^{2}\right)$ mais baixo que o apresentado para os outros tipos de matérias-primas e um alto erro padrão da estimativa $\left(\mathrm{S}_{\mathrm{yx}}\right)$. Esse fato decorre da maior variabilidade que existe nas técnicas de processamento da madeira serrada e das diferentes espécies que são usadas no polo moveleiro, que causam uma maior variabilidade dos percentuais de aproveitamento obtidos por cada empresa.
Por outro lado, a estimativa dos resíduos de compensados apresentou um $\mathrm{R}^{2}$ próximo de um e um erro padrão da estimativa próximo de zero, mostrando que as empresas que trabalham com essa matéria-prima são homogêneas em relação aos processos utilizados e aos aproveitamentos obtidos.

Ao contrário dos anteriores, o modelo para estimativa dos resíduos de MDF inclui todas as variáveis de produção testadas, mostrando que sua utilização melhora a precisão da estimativa. Isso mostra que essas variáveis têm influência na quantidade de resíduos de MDF gerados. É possível verificar também que a quantidade de resíduos de MDF gerados por cada empresa aumenta com o aumento do número de colaboradores e com o aumento do consumo de água. Ao contrário, diminui com o aumento da quantidade de matéria-prima total utilizada, com o aumento do número de máquinas e com o aumento da quantidade de energia consumida. Pode-se inferir que as maiores empresas e com maior nível de automatização geram menor quantidade proporcional de resíduos de MDF.

Por fim, o modelo para estimativa da quantidade de resíduo de aglomerado gerado inclui, além da quantidade de matéria-prima consumida, o consumo de energia. Essa variável, de certa forma, expressa o porte da empresa e por isso sua inclusão no modelo melhora a precisão da estimativa. Outras variáveis também expressam o porte da empresa, como o número de empregados, mas o consumo de energia é um fator ligado diretamente ao setor produtivo. Aqui também fica ratificado que existe homogeneidade entre os percentuais de aproveitamento das chapas aglomeradas verificados nas empresas.

No município de Lagoa Vermelha o ajuste para madeira apresentou um $\mathrm{r}^{2}$ de 0,32 e para MDF de 0,75. Esse fato decorre de existirem no município muitas empresas pequenas,

Tabela 8: Modelos para estimativa da geração de resíduos de madeira e de seus derivados, obtidos pelo método stepwise de regressão linear.

\begin{tabular}{|c|c|c|c|c|c|}
\hline Mod. & Variável dependente & Equação & $\mathrm{R}^{2}$ & $\mathrm{~S}_{\mathrm{yx}}$ & $\mathrm{F}$ \\
\hline 1 & Resíduo de madeira & $\mathrm{RESM}=-3,571+0,532 \mathrm{MAD}$ & 0,886 & 29,85 & 717 \\
\hline 2 & Resíduo de compensado & RESC $=0,074+0,050$ COMP & 0,997 & 0,67 & 28609 \\
\hline 3 & $\begin{array}{l}\text { Resíduo de } \\
\text { MDF }\end{array}$ & $\begin{array}{c}\text { RESMDF }=-0,915+0,050 \text { MDF }+0,052 \text { COL }-0,002 \\
\text { MP - 0,088 MAQ + 0,028 ÁGUA - 1,725.10 } 10^{-5} \text { EN }\end{array}$ & 0,920 & 6,24 & 179 \\
\hline 4 & Resíduo de aglomerado & RESAGL $=-0,035+0,049$ AGLO $+5,788 \cdot 10^{-5} \mathrm{EN}$ & 0,937 & 14,11 & 694 \\
\hline
\end{tabular}

Legenda: MOD = MODELO; RESM = Resíduo de madeira; RESC = Resíduo de compensado; RESMDF = Resíduo de MDF; RESAGL = Resíduo de aglomerado; MAD = Consumo de madeira; COMP = Consumo de compensado; MDF = Consumo de compensado; $\mathrm{COL}=\mathrm{Número}$ de colaboradores; $\mathrm{MP}=$ Consumo de matéria-prima total; $\mathrm{MAQ}=$ Número de máquinas; ÁGUA = Consumo de água; EN = Consumo de energia. 
com pouco consumo de madeira serrada, que informaram percentuais de aproveitamento mais altos que a média geral verificada para esse tipo de matéria-prima. Sendo assim, a média de aproveitamento da madeira serrada nesse município foi de $88,38 \%$ contra uma média geral de $66,51 \%$ (vide Tabela 2). Nas Figuras 2 e 3 são apresentados os gráficos da quantidade de resíduos gerados em função da quantidade de matéria-prima consumida para cada tipo de matéria-prima, separados por município.

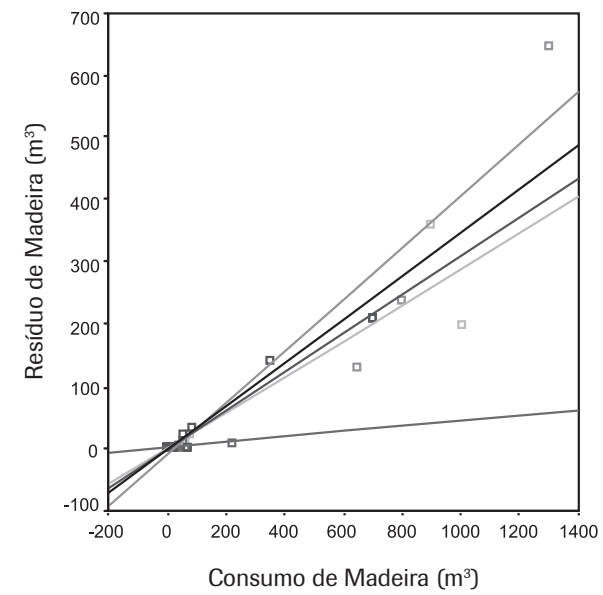

É possível verificar que existe homogeneidade entre os percentuais de aproveitamento das empresas, considerando os tipos de matéria-prima separadamente, em cada município. Apenas três situações apresentaram um coeficiente de determinação $\left(R^{2}\right)$ para a regressão inferior a 0,85 .

No município de Lagoa Vermelha o ajuste para madeira apresentou um $\mathrm{R}^{2}$ de 0,32 e para MDF de 0,75. Esse fato decorre de existirem no município muitas empresas pequenas, com pouco consumo de madeira serrada, que informaram

Figura 2: Quantidade de resíduo de madeira (a) e de mdf (b), em função da quantidade de matéria-prima consumida, com a linha de regressão linear ajustada por município.

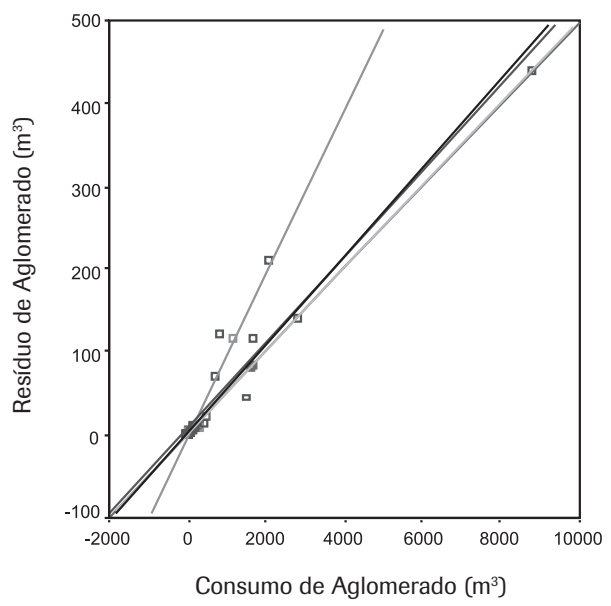

$$
\begin{aligned}
& \text { Município } \\
& \begin{array}{l}
\square \text { Lagoa Vermelha } \\
\text { Rsq }=0,9667
\end{array} \\
& \hline \square \text { Flores da Cunha } \\
& \text { Rsq }=0,9775 \\
& \square \text { Caxias do Sul } \\
& \text { Rsq }=0,9952 \\
& \hline \square \text { Bento Gonçalves } \\
& \text { Rsq }=0,9225 \\
& \hline \text { Total } \\
& \text { Rsq }=0,9244
\end{aligned}
$$

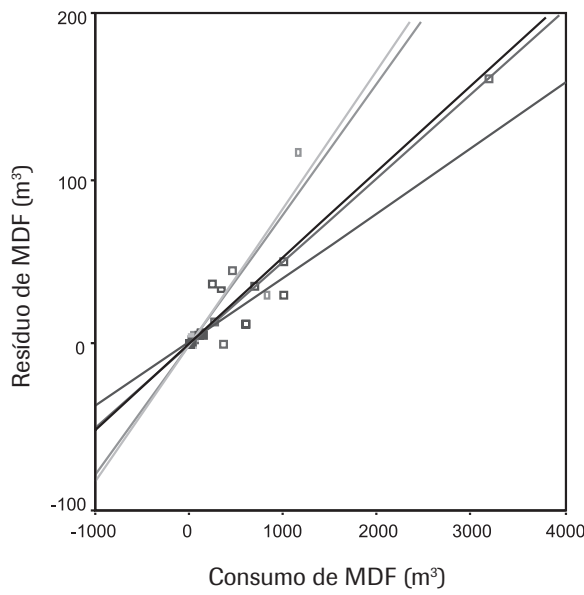

Município

$\square$ Lagoa Vermelha Rsq $=0,9665$

$\square$ Flores da Cunha $\mathrm{Rsq}=0,8481$

$\square$ Caxias do Sul Rsq $=0,8692$

$\square$ Bento Gonçalves $\mathrm{Rsq}=0,7005$

Total

Rsq $=0,8621$

Consumo de MDF $\left(\mathrm{m}^{3}\right)$

Figura 3: Quantidade de resíduo de aglomerado (a) e de compensado (b), em função da quantidade de matéria-prima consumida, com a linha de regressão linear ajustada por município. 
percentuais de aproveitamento mais altos que a média geral verificada para esse tipo de matéria-prima. Sendo assim, a média de aproveitamento da madeira serrada nesse município foi de $88,38 \%$ contra uma média geral de $66,51 \%$ (vide Tabela 2).

No município de Bento Gonçalves, o $\mathrm{R}^{2}$ do ajuste para MDF foi de 0,70. Nesse caso, embora a média de aproveitamento das empresas do município tenha sido semelhante à média geral, ocorreu uma maior dispersão dos percentuais de aproveitamento de cada empresa, que variaram de $85 \%$ a $98 \%$. Assim, nesse município, pode-se inferir que o ajuste apresenta um erro padrão da estimativa maior.

\section{CONCLUSÕES}

A indústria moveleira da Serra Gaúcha gera uma significativa quantidade de resíduo de madeira e derivados que, segundo a análise multivariada, pode ser caracterizada em função do porte da empresa e da matéria-prima usada.

A maior quantidade de resíduo gerado no polo moveleiro provém da madeira serrada, seguida do aglomerado, do
MDF e do compensado, respectivamente. Foi estimada uma geração de 1381 toneladas de serragem de madeira, 331,99 de MDF e 1209,11 de aglomerado nos municípios pesquisados. Esses municípios representam aproximadamente $70 \%$ da produção de móveis do Estado do Rio Grande do Sul.

A quantidade de resíduo gerado por classe de matériaprima, para determinada empresa ou determinado município pesquisado, pode ser estimada em função das variáveis: quantidade de matéria-prima consumida, número de colaboradores, número de máquinas, consumo de energia e consumo de água. Para os resíduos de madeira e para os resíduos de compensados, a inclusão das variáveis de produção não proporcionou melhora na precisão da estimativa. Ao contrário, o modelo para estimativa dos resíduos de MDF inclui todas as variáveis de produção testadas, mostrando que sua utilização melhora a precisão da estimativa. O modelo para estimativa da quantidade de resíduo de aglomerado gerado inclui, além da quantidade de matéria-prima consumida, o consumo de energia. A metodologia utilizada no trabalho mostrou ser uma eficiente ferramenta para avaliação do potencial gerador de resíduos no segmento madeira-móveis quando consideradas as 16 variáveis de produção pesquisadas.

\section{Artigo recebido em 27/10/2007 Aprovado para publicação em 26/03/2009}

\section{REFERÊNCIAS}

ALIEVE, R. M.; VARGAS, M. A. Competitividade, capacitação tecnológica e inovação no arranjo produtivo moveleiro da Serra Gaúcha/RS Brasil. In: Polos Moveleiros II - Linhares (ES) III - Ubá (MG) IV - Bento Gonçalves (RS). São Paulo: Abimóvel, 2002. 214 p.

ARIMA, E.; VERÍSSIMO, A.; SOUZA JR., C. A Atividade Madeireira e Desmatamento na Amazônia. IICA - Embrapa, 1999. 56 p.

BRAND, M. A.; HASSEGAWA, M. Determinação da quantidade de resíduos madeiráveis gerados nas indústrias madeireiras em um raio de 150 km do município de Otacílio Costa. Lages: Universidade do Planalto Catarinense, 2005. $67 \mathrm{p}$.

BRAND, M. A.; KLOCK, U.; MUÑIZ, G. I. B.; SILVA, D. A. Avaliação do processo produtivo de uma indústria de manufatura de painéis por meio do balanço de material e do rendimento da matéria-prima. Revista Árvore, Viçosa-MG, v. 28, n. 4 , p. 553-562, 2004.

ECKER, V.; CUNHA A. B.; MODESTI, L. G. Avaliação do processo produtivo de uma indústria de painéis sarrafeados. In: CONGRESSO FLORESTAL BRASILEIRO, 8., 2003, São Paulo. Anais... São Paulo: 2003. p. 313-314.

FAO (Organización de las Naciones Unidas para la Agricultura y la Alimentación). Actas de la consulta mundial sobre paneles a base de madera. Roma, 1975. 245 p.

GERWING, J.; VIDAL, E.; VERÍSSIMO, A.; UHL, C. Rendimento no Processamento de Madeira no Estado do Pará. Série Amazônia, n.18. Belém: Imazon, 2001. 38 p.

GONÇALVES, M. T. T. Processamento da madeira. Bauru: SP, 2000. 242 p.
GUÉRON, A. L.; GARRIDO, V. Requisitos ambientais, acesso a mercados e competitividade na indústria de madeira e móveis do Brasil. Ponto Focal de Barreiras Técnicas às Exportações. Rio de Janeiro: Inmetro, 2004. 38 p.

HIERARQUIA SOCIOECONÔMICA DE BENTO GONÇALVES. Bento Gonçalves: CFP Senai de Artes Gráficas, 2000. 29. ed. 144 p.

HILLIG, É.; SCHNEIDER, V. E.; PAVONI, E. T. Diagnóstico da geração de resíduos e dos sistemas de gestão ambiental das empresas do pólo moveleiro da serra Gaúcha. In: Polo moveleiro da Serra Gaúcha: Geração de resíduos e perspectivas para sistemas de gerenciamento ambiental. Caxias do Sul: Educs, 2004. 165 p.

IBQP - Instituto Brasileiro de Qualidade e Produtividade do Paraná. Análise da competitividade da cadeia produtiva da madeira no estado do Paraná. Curitiba: IBQP, 2002. 345 p. 
INSTITUTO PRÓ-NATURA. Manejo Florestal e Geração de Resíduos Energéticos no Noroeste de Mato Grosso. Campo Grande: Instituto PróNatura, 2002. $15 \mathrm{p}$.

KOCK, P. Material balances and energy required for manufacture of ten wood commodities. Energy and the wood products industry. Georgia: Forest Products Research Society, 1976. 173p.

LIMA, E. G. Diagnóstico ambiental de empresas de móveis em madeira situadas no polo moveleiro de Arapongas - PR. 2005. 134 p. Dissertação (Mestrado em Ciências Florestais) - Universidade Federal do Paraná, Curitiba.

MORAES, M. A. F. D. Estudo da competitividade de cadeias integradas no Brasil: impactos das zonas de livre comércio. Cadeia: Madeira e Móveis. Nota Técnica Final. UNICAMP-IE-NEIT, Campinas, 2002. 212 p.
OLANDOSKI, D. P. Rendimento, resíduos e considerações sobre melhorias no processo em indústrias de chapas compensadas. 2001, 85 f. Dissertação (Mestrado em Ciências Florestais). Universidade Federal do Paraná, Curitiba, 2001.

POLZL, W. B. Eficiência produtiva e econômica do segmento industrial da madeira compensada no Estado do Paraná. 2002, 114 f. Dissertação (Mestrado em Ciências Florestais). Universidade Federal do Paraná, Curitiba, 2002.

RADIOBRAS - CIÊNCIA, TECNOLOGIA \& MEIO-AMBIENTE Serrarias geram $620 \mathrm{mil}$ toneladas de serragem por ano. www.radiobras. gov.br/abrn/c\&t/1997/ coluna_090597.htm. Acesso: maio 1997

ROESE, M. Política industrial e de C\&T regional: sistemas de inovação regionais. $\mathrm{O}$ caso da aglomeração moveleira de Bento Gonçalves / RS. Revista Eletrônica de Administração, v. 6, n. 4, UFRGS, 2000.

SCHNEIDER, V. E.; HILLIG, É.; BERTOTTO FILHO, L. A.; RIZZON, M. R. Geração de resíduos de madeira e derivados no Polo Moveleiro da Serra Gaúcha - Diagnóstico e indicativos para o gerenciamento ambiental na indústria moveleira. In: XI Simpósio Luso-Brasileiro de Engenharia Sanitária e Ambiental, 2004 Natal - RN - Brasil. Anais... Rio de Janeiro/RJ: Associação Brasileira de Engenharia Sanitária e Ambiental, 2004

SILVA, J. C. G. L. da. Análise da eficiência econômica da indústria de compensados do estado do Paraná. 1987. 155 f. Dissertação (Mestrado em Ciências Florestais). Universidade Federal do Paraná, Curitiba, 1987.

\section{SOBRE OS AUTORES}

\section{Éverton Hillig}

Universidade Estadual do Centro-Oeste

End.: PR 153 - Km 07 - Riozinho - 84500-000 - Irati - PR

Tel.: (42) 3421-3000 - ramal: 3088 Fax: (42) 3421-3000 - ramal: 3016

E-mail: hillig@hotmail.com

\section{Vania Elisabete Schneider}

Universidade de Caxias do Sul

End.: Rua Francisco Getúlio Vargas, 1130 - Cidade Universitária - Bloco V - Bairro Petrópolis. 95070-560 - Caxias do Sul - RS Tel.: (54) 3218-2100 - ramal: 2508 Fax: (54) 3218-2100 - ramal: 2507

E-mail: veschnei@ucs.br

\section{Elóide Teresa Pavoni}

Universidade de Caxias do Sul

End.: Rua Francisco Getúlio Vargas, 1130 - Cidade Universitária - Bloco V - Bairro Petrópolis. 95070-560 - Caxias do Sul - RS

Tel.: (54) 3218-2100 - ramal: 2508 Fax: (54) 3218-2100 - ramal: 2507

E-mail: etpavoni@ucs.br 